\title{
MARGEM DE APRECIAÇÃO E DEFERÊNCIA DA JURISDIÇÃO CONSTITUCIONAL
}

\section{MARGIN OF APPRECIATION AND CONSTITUTIONAL REVIEW DEFERENCE}

\author{
Anizio Pires Gaviao Filho \\ Faculdade de Direito da Fundação Escola Superio do Ministério Público \\ Bianca Medran Moreira ${ }^{2}$ \\ Faculdade de Direito da Fundação Escola Superio do Ministério Público
}

\begin{abstract}
Resumo:
O presente estudo tem por escopo analisar o problema da dimensão institucional da aplicação do teste da proporcionalidade pela jurisdição constitucional para controlar as decisões do legislador sobre restrições a direitos fundamentais. Cuida-se de investigação assentada em pesquisa bibliográfica, desenvolvida com base no método dedutivo, que pretende demonstrar, primeiramente, que a objeção da ilegitimidade pode ser superada por meio de um controle moderado, justificado e de argumentação racional e, segundo, que a teoria da margem de apreciação desempenha papel central para a justificação da deferência judicial.
\end{abstract}

Palavras-chave:

Proporcionalidade. Dimensão institucional. Legitimidade. Margem de apreciação. Deferência judicial.

\begin{abstract}
:
The purpose of this work is to analyse the problem of the institutional dimension of the application of the proportionality test by the constitutional jurisdiction to control the decisions of the legislator regarding restrictions on constitutional rights. The study is based on bibliographic research, developed based on the deductive method, which aims to demonstrate, first, that the objection of illegitimacy can be overcome through moderate control and rational argumentation, and second, that the theory of the margin of discretion plays a central role in justifying judicial deference.
\end{abstract}

Keywords:

Proporcionality. Institutional dimension. Legitimacy. Margin of appreciation. Juditial deference.

\section{INTRODUÇÃO}

A presente investigação trata de umas das mais potentes objeções ao teste da proporcionalidade, normalmente aplicado no âmbito da jurisdição constitucional e infraconstitucional, para o controle das intervenções, restrições ou limites impostos aos direitos

\footnotetext{
1 Doutor em Direito (Universidade Federal do Rio do Rio Grande do Sul - UFRGS). Mestre em Direito (Universidade Federal do Rio do Rio Grande do Sul - UFRGS). Prof. Coordenador do Programa de Pós-Graduação Stricto Sensu em Direito - Mestrado Acadêmico - da Faculdade de Direito da Fundação Escola Superior do Ministério Público - PPGD/FMP. Prof. Titular da Faculdade de Direito da Fundação Escola Superior do Ministério Público. Prof. Coord. Grupo de Pesquisa "Colisão de Direitos Fundamentais e Direito como Argumentação" do PPGD/FMP. Procurador de Justiça, RS. E-mail: piresgaviao@ hotmail.com.

2 Advogada. Bacharel em Direito pela Puntifícia Universidade Católica do Rio Grande do Sul (PUCRS). Especialista em Direito Constitucional pela Puntifícia Universidade Católica do Rio Grande do Sul (PUCRS). Mestranda em Direito na Programa de Pós-Graduação Stricto Sensu da FAculdade de Direito da Fundação Escola Superior do Ministério Público (FMP/RS - PPGD). Integrante do Grupo de Estudos do Projeto de Pesquisa Colisão de Direitos Fundamentais e o Direito como Argumentação, coordenado pelo Prof. Dr. Anizio Pires Gavião Filho do Programa de Pós-Graduação em Direito da Fundação Escola Superior do Ministério Público e vinculado no CNPq ao Grupo de Estudos Tutelas à Efetivação dos Direitos Transindividuais.
} 
fundamentais. Ela diz que os tribunais não possuem legitimidade para realizar as valorações que a aplicação da ferramenta exige e que, ao aplicar critérios de ponderação, para resolver conflitos entre direitos fundamentais, exercem intervenções ilegítimas na competência legislativa, democraticamente definida.

Trata-se de tema que encontra terreno fértil em tempos de ativismo judicial, notadamente porque coloca em relação as escolhas políticas do legislador, democraticamente legitimado, e a atuação da jurisdição no controle dessas escolhas, em nome da proteção dos direitos fundamentais. Com isso, fica colocada não somente a tensão entre democracia e primazia pela proteção dos direitos fundamentais, mas também a determinação dos espaços de competência entre a margem de apreciação discricionária do legislador e o que está sujeito ao controle da jurisdição constitucional. Se os juízes e tribunais responsáveis por esse controle não prestarem deferência à margem de apreciação discricionária de escolhas políticas do legislador democraticamente legitimado, o resultado é a usurpação da competência funcional do legislador pela jurisdição constitucional, com prejuízos à democracia.

O que segue tem o propósito de apresentar critérios para a justificação da deferência jurisdicional às decisões do legislador, com base no reconhecimento de margens de apreciação. Nesse sentido, em primeiro lugar, serão detalhados os problemas da dimensão institucional e as principais críticas a respeito da legitimidade da jurisdição constitucional para aplicar o teste de proporcionalidade. Em segundo lugar, será apresentada a teoria da margem de apreciação como alternativa para dar conta do problema da dimensão institucional da aplicação do teste da proporcionalidade.

O que se pretende é oferecer uma contribuição para o permanente e atual debate colocado ao constitucionalismo global a respeito da tensão entre democrática e direitos fundamentais, notadamente quanto ao emprego do teste da proporcionalidade pela jurisdição constitucional.

Com o intuito de aprofundar a discussão, tanto sobre uma das mais duras críticas feitas à análise de proporcionalidade, quanto sobre a temática da deferência jurisdicional ao decidido no âmbito da margem de apreciação do legislador democraticamente legitimado, a pesquisa bibliográfica, através do método dedutivo, busca demonstrar e entender, principalmente, se e como a crítica da ilegitimidade pode ser superada. A proposição central oferecida à reflexão é a de que o controle jurisdicional, exercido com base no teste da proporcionalidade, deve respeitar a margem de apreciação do legislador democraticamente legitimado. 


\section{O PROBLEMA DA DIMENSÃO INSTITUCIONAL DO TESTE DA PROPORCIONALIDADE E A MARGEM DE APRECIAÇÃO}

No constitucionalismo global, o teste da proporcionalidade tem sido a metodologia normalmente aplicada pela jurisdição constitucional para verificar se os limites ou restrições a direitos fundamentais, impostas por medidas estatais, sejam originárias de decisões da administração, sejam de escolhas políticas do legislador democraticamente legitimado, estão justificadas (ALEXY, 2007a, p. 52-53; ALEXY, 2015, p. 30). Se o decidido no âmbito da margem de atuação da administração ou no âmbito da margem de atuação do legislador supera a análise da proporcionalidade, então a medida estatal imposta está justificada, ainda que representativa de violação e restrição a direito fundamental.

O problema é que o emprego do teste da proporcionalidade, pela jurisdição constitucional, representa risco para democracia, notadamente ao poder implicar usurpação da margem de apreciação do legislador para conformar os direitos fundamentais por parte da atividade jurisdicional. É acertado afirmar que o teste da proporcionalidade é verdadeiro antídoto e melhor resposta para o problema da juristocracia, pois, com ele, podem ser identificadas mais facilmente as valorações feitas pelos julgadores (YOUNG, 2017, p. 13).

Por outro lado, é igualmente certo que compete ao legislador, legitimamente escolhido, definir no âmbito de suas escolhas políticas, os direitos e interesses predominantes. Nesse sentido, Forsthoff (1975, p. 233), deixa saber que o teste da proporcionalidade e a ponderação, quando aplicados pelos tribunais constitucionais para resolver colisão de direitos fundamentais reduz a esfera de atuação que corresponde ao legislador no processo de articulação dos interesses sociais e de configuração da vida política:

\footnotetext{
Quando o juiz administrativo utiliza o princípio da proporcionalidade, ele controla a discrição da Administração, com referência a uma estrutura legal específica. Por outro lado, quando o juiz constitucional aplica esse princípio, ele escolhe pelo Legislador, impõe suas opções de avaliação e usurpa sua competência para moldar a vida política da sociedade. Como consequência, o princípio mencionado perde seu caráter como um critério para a aplicação das disposições legais e é transfigurado em um truque para justificar as intervenções ilegítimas do Tribunal Constitucional dentro da competência do Parlamento (FORSTHOFF, 1975, p.233).
}

Por isso mesmo, então, o teste da proporcionalidade, aplicado pela jurisdição constitucional, configura perigoso instrumento de intervenção no espaço de atuação democrática do legislador. Ele seria aceitável, no controle da discricionariedade administrativa, com referência a um marco jurídico concreto, mas completamente descabido, se feito pelo juiz 
constitucional. Outro ponto importante é que as ponderações dos tribunais poderiam encontrar justificação, mais facilmente, pela necessidade de uma decisão autorizativa, em casos de conflitos horizontais entre partes que estejam em situação de igualdade, porém o controle de preferências estatais já existentes e reguladas não encontraria justificação no marco da divisão institucional de competências.

Contrário ao controle jurisdicional sobre a discricionariedade do legislador na conformação da vida política da sociedade e dos direitos fundamentais, Aleinnikoff (1987, p. 952) questiona a legitimidade da própria jurisdição constitucional, em um Estado que pretende ser democrático. O seu argumento mais emblemático é o de que, quando o juiz constitucional leva a cabo uma ponderação, exerce a função de harmonizar interesses sociais e isso, em todo Estado democrático, é atribuído ao legislador. Ainda na hipótese de o processo legislativo ignorar direitos e interesses de minorias e de grupos vulneráveis, a jurisdição constitucional não estaria legitimada para ponderar bens e interesses conflitantes, no âmbito dos direitos fundamentais.

Dessa forma os tribunais poderiam, no máximo, suspender temporariamente a vigência de uma determinada lei, enquanto o legislador fosse convocado a modificá-la, e nem mesmo o sedutor argumento da tutela de minorias teria força suficiente para conferir legitimidade ao tribunal constitucional para a prática da ponderação no âmbito dos direitos fundamentais. Assim, a aplicação do teste da proporcionalidade, pela jurisdição constitucional, no exercício do controle de vinculação do legislador aos direitos fundamentais, simplesmente, não encontraria, sob nenhum ângulo, legitimidade justificada.

Aliás, a respeito da célebre decisão Lochner da Suprema Corte dos Estados Unidos da América, que decretou a nulidade de legislação do Estado de Nova York, que disciplinava sobre a carga de horas de trabalho dos empregados de padarias, estabelecendo o máximo de dez (10) horas diárias, com base no argumento de que as disposições jurídicas nela contidas violava o direito fundamental de liberdade de contratar, costuma-se apontar exatamente o aspecto de que é no espaço do legislador, e não no tribunal constitucional, o lugar de ponderar, sopesar e comparar os direitos e interesses eventualmente conflitantes em determinada situação. A ponderação não é tarefa da jurisdição constitucional, mas do legislador. Ao tratar desse tema, Sieckmann diz que: 
"Estado jurisdicional", que seria problemático à luz dos princípios da democracia e da divisão de poderes (SIECKMANN, 2014, p. 316).

A questão que se coloca é se esses argumentos podem ser superados. Essa elaboração indaga pela formulação de critérios que podem conciliar o espaço de atuação do legislador democraticamente eleito e o controle da jurisdição constitucional sobre a proteção dos direitos fundamentais. O que se tem sustentado é que tanto o legislador como a jurisdição constitucional devem aplicar o teste da proporcionalidade em favor da otimização dos direitos fundamentais em maior grau tanto quanto possível, com respeito às possibilidades fáticas e jurídicas (ALEXY, 2007a, p. 92). E isso equivale a dizer que, tanto legislador, quanto tribunais constitucionais, possuem competência para a interpretação e aplicação dos direitos fundamentais.

Uma alternativa oferecida a superar o problema da dimensão institucional da jurisdicional constitucional para realizar ponderações sobre direitos fundamentais e controlar o decidido pelo legislador democraticamente legitimado é a teoria da margem de apreciação (ALEXY, 2008, p. 583; KLATT, 2012, p. 78). Ela tem a vantagem de conciliar a ideia de constituição como ordenação fundamental e ordenação-quadro. Uma constituição como ordenação fundamental determina tudo, o que significa que o dado na constituição determina o conteúdo total da ordem jurídica. Uma constituição como ordenação fundamental é incompatível com democracia, pois reduz a zero o espaço de ponderações do legislador. Uma constituição pode determinar muitas coisas, mas não tudo, deixando espaço para as escolhas políticas do legislador.

As margens de apreciação do legislador democraticamente legitimado são a estrutural e a epistêmica.

$\mathrm{Na}$ margem de apreciação estrutural, o legislador está liberado para escolher as finalidades, as medidas a serem adotadas e o grau de realização dos direitos fundamentais e dos bens coletivos constitucionalmente protegidos ou o interesse público (RIVERS, 2007, p. 170). Evidentemente, a determinação da margem estrutural está na dependência da relação entre os três testes parciais, principalmente a relação entre o teste da necessidade e o teste da proporcionalidade em sentido restrito, ou seja, a ponderação (RIVERS, 2007, p. 171).

A margem de apreciação estrutural define-se pela ausência de ordens e proibições definitivas. Quando a constituição não ordena e nem proíbe uma determinada ação, ela deixa o legislador liberado para determinar finalidade, escolher meios e fazer ponderações. O que a constituição libera definitivamente pertence à margem de apreciação estrutural e sobre ela não 
há controle judicial-constitucional, porque ali termina a normatividade material definitiva da constituição (ALEXY, 2007a, p. 79).

A margem de apreciação estrutural pode ser usada para a determinação de finalidade, escolha do meio e fazer ponderação. Há margem de apreciação para determinação da finalidade pelo legislador quando o direito fundamental contém uma autorização de intervenção, mas não ordena ou proíbe uma determinada ação. O legislador é livre não somente para selecionar a finalidade como também para escolher a medida da sua realização. O teste da idoneidade serve para excluir uma medida inidônea. Cuida-se de um critério negativo que exclui todas as medidas não idôneas, mas deixa aberta margem de apreciação do legislador para a escolha de todas as outras medidas idôneas. A margem de apreciação do legislador para livremente escolher os fins é ampla e assim extensa deve ser a deferência jurisdicional. Ele pode escolher entre os mais variados fins legítimos. O único limite dado ao legislador é em relação a medidas que, de nenhum modo, contribuem para a realização do fim (KLATT, 2012, p. 79). Evidentemente, a liberdade do legislador para determinar a finalidade depende do que estabelecem os outros dois testes parciais da proporcionalidade (ALEXY, 2007a, p. 80). Mas, então, se o teste da idoneidade não determina tudo, deixando margem livre para outras medidas idôneas, então ele se mostra compatível com a constituição como ordenação-quadro.

Não é diferente o que ocorre com o teste da necessidade. Como critério negativo, ele serve para excluir, dentre as medidas idôneas, as medidas mais gravosas. Dizer que o legislador, ao perseguir o seu objetivo de prevenir doenças, deve escolher as medidas com menor intensidade de intervenção em outros princípios ou bens coletivos não significa exigência de otimização ao ponto máximo, mas implica evitar sacrifícios desnecessários. Se o teste parcial da necessidade não determina tudo, deixando aberta a margem de ação para escolha de qualquer das medidas necessárias, então não há incompatibilidade com a constituição como ordenaçãoquadro (ALEXY, 2002, p. 399).

A margem de apreciação para a escolha dos meios aparece quando os direitos fundamentais não somente proíbem intervenções, mas, também, ordenam ações positivas, especialmente de proteção. Quando várias medidas são igualmente idôneas para alcançar uma finalidade, o legislador pode livremente escolher qualquer uma delas (KLATT, 2012, p. 79). Contudo, se eles realizam a finalidade em diferentes graus ou se não há segurança quanto o grau de realização dessa finalidade, coloca-se a questão da combinação de margens de apreciação. A questão não se resolve apenas pela margem de apreciação estrutural. Nesse caso, a determinação da medida necessária e proporcional depende da margem da ponderação e da margem de apreciação epistêmica, considerando a intensidade de intervenção em outros direitos 
fundamentais ou bens jurídicos coletivos constitucionalmente protegidos. O limite traçado para o legislador é o de que estão proibidas, dentre as medidas igualmente idôneas, apenas as medidas mais gravosas. Fora disso, o legislador é livre e nada lhe é determinado positivamente.

A margem de apreciação da ponderação é parte essencial da teoria da margem de apreciação, correspondendo ao papel que nela desempenha o teste da proporcionalidade (ALEXY, 2007a, p. 81). Otimização dos direitos fundamentais não é otimização máxima. O grau de otimização depende sempre das possibilidades fáticas e jurídicas. A compatibilidade entre ponderação e a constituição como ordenação-quadro depende de se, pela ponderação mesma, algo resulta determinado ou não resulta determinado. A lei material da ponderação diz que quanto maior a intensidade da intervenção em um direito fundamental, maior deve ser a importância da realização de outro direito fundamental. É a partir dessa formulação que se pode verificar o que a Constituição ordena ou proíbe definitivamente. Quando o resultado da ponderação é um empate, a Constituição nada decide. Ela simplesmente libera o que reside no quadro. O liberado é a margem de apreciação estrutural de conformação, de atuação e de ponderação livres para o legislador (ALEXY, 2007b, p. 369).

A margem de apreciação epistêmica empírica permite intervenção nos direitos fundamentais com base em premissas fáticas incertas, sustentáveis ou plausíveis. A extensão da margem de apreciação epistêmica corresponde à extensão de possíveis divergências entre o realmente ordenado, proibido e liberado e aquilo que é verificável empiricamente como ordenado, proibido e liberado.

A ignorância fática sobre a idoneidade da medida escolhida para realização da finalidade e, também, sobre a necessidade da medida configura a margem de apreciação epistêmica empírica do legislador. Assim, acha-se na margem de apreciação epistêmica empírica do legislador a liberdade para escolher medidas que muito provavelmente contribuam para a realização da finalidade e medidas que parecem implicar menor intervenção nos direitos fundamentais ou bens jurídicos coletivos constitucionalmente protegidos. A exigência de certeza inviabilizaria a atuação do legislador, comprometendo os princípios formais da divisão dos poderes e da democracia, que exigem alguma margem de apreciação do conhecimento empírico (ALEXY, 2007a, p. 90).

Um caso paradigmático de reconhecimento da margem epistêmica empírica está na decisão do Tribunal Constitucional Federal alemão ao examinar a constitucionalidade da penalização do uso de maconha, quando entendeu que, se a ciência discorda acerca dos efeitos maléficos da cannabis em geral ou da maconha, sobretudo em relação às outras drogas, deve prevalecer a decisão do legislador. A decisão do Tribunal Constituição Federal, ao realizar a 
análise da proporcionalidade de forma estruturada e apreciar os requisitos da adequação e da necessidade do meio selecionado para atingir o fim almejado, entendeu que, cabe ao legislador, uma margem discricionária de avaliação, que só pode ser revista de forma limitada. Nesse sentido, a proporcionalidade só serve para evitar abusos e o legislador já teria avaliado os perigos que ameaçam o indivíduo ou a sociedade:

Na avaliação da adequação e da necessidade do produto escolhido, em conformidade com o princípio da proporcionalidade, a fim de atingir o objetivo pretendido e em relação com o mesmo. A avaliação e o prognóstico dos perigos que ameaçam o indivíduo ou o público em geral têm uma margem de discricionariedade para o legislador, que só pode ser revista até certo ponto pelo Tribunal Constitucional Federal (BVerfGE 90, 145).

Na hipótese de espaços da margem de apreciação, o legislador estaria liberado para fazer as suas escolhas sobre finalidades, medidas e intensidade interventiva, valorando os direitos fundamentais e os bens coletivos. Em outra decisão, o Tribunal Constitucional Federal alemão deixou assentado que:

Quando o Legislativo está constitucionalmente obrigado a empregar meios eficazes e suficientes para proteger um interesse jurídico, ele detém discricionariedade de valoração e de escolha política. (BVerfGE 88, 203).

Uma questão central para ser destacada em favor do reconhecimento da margem de apreciação está exatamente na incapacidade de os juízes e tribunais reuniram as condições necessárias para realizar investigações empíricas exigidas para o melhor conhecimento da situação posta em consideração. Nesse sentido, Klatt (2015, p. 266) observa:

\footnotetext{
Há duas variáveis dessa objeção. Uma aponta para os limites da expertise e a outra para a legitimidade do judiciário, respectivamente. A variável da expertise sustenta que os Tribunais, em geral, não estão capacitados para lidar com questão complexas e de alto impacto político. Em contraste com o Legislativo, os Tribunais não estariam amparados por um vasto aparato burocrático apto a elaborar e a processar informações em ampla variedade de temas e matérias. Afora isso, os Tribunais têm apenas limitada expertise em teoria política e ética.
}

A margem de apreciação epistêmica normativa trata diretamente do conteúdo material da constituição e está relacionada ao peso dos direitos fundamentais em colisão, bem como ao que é deixado para as valorações próprias do legislador (ALEXY, 2002, p. 415). A incerteza descansa na intensidade da intervenção sobre um direito fundamental ou sobre quanto efetivamente pesa a intervenção no direito fundamental ou bem coletivo. As incertezas normativas colocam três aspectos diferentes: $a$ ) como graduar diferentes intensidades de 
intervenção e de importâncias de realização de um princípio; $b$ ) incerteza quanto ao peso abstrato dos princípios; $c$ ) incerteza quanto ao peso concreto dos princípios relacionados uns com os outros (RIVERS, 2007, p. 178).

Na margem de apreciação epistêmica normativa, o legislador está liberado para escolher livremente conforme suas próprias valorações. A questão que se coloca a partir disso é como compatibilizar a margem de apreciação epistêmica normativa com a vinculação à constituição. É que margem de apreciação epistêmica normativa significa uma supressão do controle judicialconstitucional da vinculação à constituição. Na extensão completa da área coberta pela margem epistêmica normativa, não há controle sobre o estabelecido vinculativamente pela Constituição (ALEXY, 2007a, p. 91). A existência da margem de apreciação epistêmica normativa não pode ser levar à configuração de uma área absolutamente livre e incontrolável para a quantificação dos direitos fundamentais. A necessidade de margem conformação do legislador deve ser compatibilizada com a vinculação do próprio legislador aos direitos fundamentais. O primeiro passo é que uma margem epistêmica normativa somente surge quando houver incerteza normativa quanto à ponderação dos direitos fundamentais. Se não houver incerteza quanto à ponderação de direitos fundamentais, não há margem epistêmica normativa para o legislador realizar livremente a sua própria ponderação.

O reconhecimento da margem de apreciação do legislador democraticamente legitimado não impede que o teste da proporcionalidade seja aplicado pela jurisdição constitucional para controlar as medidas estatais limitadoras ou restritivas de direitos fundamentais. Apenas, contudo, chama atenção para a necessidade de que ele seja adequado. Isso significa, que esse controle jurisdicional não seja tal que violações a direitos fundamentais não sejam impedidas e também que a margem de apreciação do legislador democraticamente legitimado seja inexistente. Com isso, fica assegurado tanto espaço para as decisões do legislador livres de controle jurisdicional, como também a intervenção da jurisdição constitucional quando o dado pelo legislador democraticamente legitimado viola os direitos fundamentais injustificadamente.

Não está em discussão apenas a competência da jurisdição constitucional para ser a guarda da Constituição. A histórica da prática dos tribunais constitucionais do pós-guerra na proteção dos direitos fundamentais e da própria ordem constitucional já assentou a correção das formulações de Hans Kelsen no célebre debate estabelecido com Carl Schmidt, na primeira metade do século passado. O problema não é quem tem competência para controlar as decisões do legislador sobre intervenções em direitos fundamentais, mas quem controla as decisões da jurisdição constitucional sobre o decidido pelo legislador democraticamente legitimado e como deve ser o procedimento desse controle. 
Entre o controle demasiadamente forte e o demasiadamente fraco, sobre o decidido pelo legislador democraticamente legitimado em sede de conformação e ponderação de direitos fundamentais, a teoria da margem de apreciação propõe o controle moderado e é decisiva porque fundamenta a conciliação entre direitos fundamentais e democracia ao formular, entre uma sobreconstitucionalização e uma subconstitucionalização, a constitucionalização adequada (ALEXY, 2007a, p. 75). Com ela, os princípios formais e, assim, a dimensão formal dos direitos fundamentais, entram em cena no jogo de princípios guiado pela proporcionalidade e ponderação. O seu mérito está em responder corretamente tanto ao não cognitivismo ${ }^{3}$ como ao cognitivismo extremo ${ }^{4}$.

\section{PONDERAÇÃO, CONTROLE MODERADO E DEFERÊNCIA IDEAL}

A jurisdição constitucional deve, de fato, verificar se as ponderações estão conformadas com os valores constitucionalmente consagrados e, quanto mais grave for a intervenção em um direito fundamental, mais intenso precisa ser o controle constitucional da justificação dessa intervenção.

Isso significa que, quanto mais grave for uma limitação de direitos fundamentais, mais evidências o tribunal exigirá de que as premissas empíricas que embasam a limitação foram corretamente estabelecidas e mais argumentos serão necessários para demostrar se escolhas políticas alternativas, menos intrusivas, foram consideradas (ALLAN, 2012, p. 218).

O controle também deve ser mais forte quanto mais alta for a importância do direito fundamental afetado. A competência do tribunal constitucional encontra, de tal forma, morada na própria ideia de sistema constitucional, fundado na prevalência da constituição.

Assim, pode-se dizer que a própria essência do constitucionalismo é a submissão da
política ao direito. Esta função distingue o direito constitucional do direito ordinário
em vários aspectos. Há, primeiro, uma diferença no objeto. O objeto do direito
constitucional é a política. O direito constitucional regula a formação e o exercício do
poder político. Os detentores do poder são os destinatários do direito constitucional.
Em segundo lugar, o direito constitucional e o ordinário têm fontes diferentes. Uma
vez que o direito constitucional traz poder político legítimo, ele não pode emanar
desse mesmo poder. É feito ou atribuído às pessoas. Em terceiro lugar, e
consequentemente, a elaboração do direito constitucional difere da elaboração da lei
ordinária. Geralmente, é um órgão especial que formula o direito constitucional e sua

\footnotetext{
${ }^{3}$ Ele diz que a jurisdição constitucional não pode cuidar da constitucionalidade material das medidas legislativas sob o ponto de vista substancial, mas somente as questões de ordem procedimental (ELY, 1980, p. 117).

${ }^{4}$ Ele diz que a jurisdição constitucional é capaz de encontrar, a partir dos precedentes, da tradição e dos princípios e dos valores atuais da comunidade, para cada caso, uma solução substancial correta (DWORKIN, 1978, p. 129130).
} 
adoção está sujeita a um procedimento especial no qual o povo toma a decisão ou, se um órgão representativo é chamado a decidir, é necessária uma maioria qualificada. Em quarto lugar, o direito constitucional difere da lei ordinária na classificação: é a lei superior. No caso de conflito entre direito constitucional e lei ordinária ou atos de aplicação da lei ordinária, o direito constitucional prevalece. O que foi regulamentado na constituição não está mais aberto a decisões políticas. E a regra da maioria não se aplica. Isso não significa total "juridificação" da política. Essa "juridificação" total seria o fim da política e a transformaria em mera administração (GRIMM, 2016, p. 202).

É de clareza solar e consagração quase que universal de que a constituição é o veículo de harmonização e unificação, que ampara todo o sistema democrático. A jurisdição constitucional é, portanto, completamente compatível com a democracia. Nas palavras da Suprema Corte Israelense:

A revisão judicial é a alma da constituição. Retire a constituição da revisão judicial e você removeu sua própria vida (...). Portanto, não é de admirar que a revisão judicial esteja sendo desenvolvida. A maioria dos estados democráticos esclarecidos tem revisão judicial ... O século XX é o século da revisão judicial (Israel, Supreme Court, United Mizrahi Bank Ltd. v. Migdal Village, Civil Appeal 6821/93,1995).

Por óbvio que a razão exige sempre moderação no uso do poder, seja pelo órgão que for. Nesse sentido, Grimm (2016, p. 200) diz que:

\begin{abstract}
A independência judicial é a salvaguarda constitucional contra a ameaça dos políticos ao exercício adequado das funções dos juízes. Ela é dirigida contra tentativas de induzir os juízes a não aplicar a lei, mas a se curvar às expectativas políticas. Esta é uma ameaça externa. Mas seria ingênuo supor que esta é a única ameaça à qual o funcionamento do sistema constitucional está exposto. Há também uma ameaça interna que vem dos próprios juízes. Ela vem em duas formas. Uma é a inclinação para seguir, voluntariamente, por que razões, expectativas políticas ou até mesmo linhas partidárias. A outra é a tentação de julgar de acordo com suas próprias preferências políticas ou ideias do que é justo e injusto, em vez de seguir padrões constitucionais. A garantia constitucional da independência judicial protege os juízes contra a política, mas não protege o sistema constitucional e a sociedade contra os juízes que, por outras razões, que não a pressão política direta, estão dispostos a desobedecer ou distorcer a lei.
\end{abstract}

O tribunal constitucional somente pode intervir mediante petição e sempre está limitado ao controle. O papel da jurisdição constitucional, ao aplicar o teste de proporcionalidade, não seria o de corrigir erros de cálculo do legislativo e, sim, o de garantir a legalidade constitucional. O tribunal só interpreta a constituição.

A contenção judicial, em uma sociedade livre, justa e democrática, assegura que, quanto mais restritiva e limitativa de direitos fundamentais for uma medida, mais ela precisa ser razoável e comprovadamente justificada, através de argumentação racional. Assim, a intepretação da constituição, pelos tribunais, será mais legítima quanto mais objetiva e racional. 
O que se espera da cultura constitucional são decisões que observem as regras processuais, refinadas pela consistência de justificação, com clareza na expressão das suas valorações e cujos argumentos tenham amparo na lógica. A legitimidade da atividade jurisdicional é, pois, argumentativa:

A objeção apresentada contra a legitimidade da jurisdição ordinária e da jurisdição constitucional para a ponderação de direitos fundamentais é respondida pela dogmática dos espaços e pela legitimidade argumentativa da atividade jurisdicional. Os juízes não são eleitos diretamente pelos representantes do povo, mas não lhes falta legitimidade para controlar intervenções em direitos fundamentais e bens coletivos constitucionalmente protegidos. (...) Se todo o poder emana do povo e em seu nome deve ser exercido, os juízes e os legisladores são os representantes do povo. (...). Não é acertado pressupor uma contradição essencial entre as funções jurisdicionais e as funções políticas. O exercício do poder não se encerra com o processo legislativo, pois, depois dele, tem continuação e, quem sabe, encontra seu real início na jurisdição e na administração. Se o "político" significa resolução de interesses, em toda a decisão judicial, em menor ou maior grau, há uma decisão própria de um poder em exercício. O conflito jurídico pressupõe um conflito de interesses ou de poder e, portanto, a controvérsia jurídica é uma controvérsia política (GAVIÃO FILHO, 2010, p. 369).

É ônus argumentativo mostrar que uma medida menos restritiva não alcançaria o mesmo fim para bem justificar prejuízo a valores constitucionais pré-estabelecidos. A verificação precisa concluir que nenhuma outra medida, menos grave, poderia atingir o objetivo relevante para que haja justificação constitucional. O grau de deferência ${ }^{5}$ depende, não só do sistema, mas geralmente do que substancialmente está em jogo.

Ademais, a discricionariedade para elaborar regras jurídicas configuradoras de intervenção em direitos fundamentais encontra limites na constituição. O limite do espaço conferido ao livre critério do legislador acaba quando começam as determinações proibitivas e obrigativas da constituição. A lei não pode definir de maneira autônoma o conteúdo dos direitos fundamentais, pois, é da constituição que o consagra, que é extraído seu conteúdo. Trata-se, assim, de uma liberdade conformada. Uma comunidade política genuína possui guardiões constitucionais independentes ao processo de representação direta e com garantias. Os direitos fundamentais limitam os representantes eleitos e o tribunal deve exercer o controle desses limites para que sejam eficazes. O legislador possui, é verdade, legitimidade democrática direta, mas, por outro lado, sofre turbulências e o calor da batalha política. A deferência é também uma questão de tradição democrática. Nesse sentido:

Um fator para determinar como o ônus da prova é distribuído entre a legislatura e os cidadãos e como os tribunais são ativistas quando o equilíbrio se torna a questão é a

\footnotetext{
5 Young (2017, p. 26) desenvolveu a taxonomia do controle judicial, classificando e caracterizando os graus de deferência nessa tipologia tripartida que não se confundiriam, segundo ela, com as ideias de controle forte e fraco.
} 
tradição democrática e revolucionária. Na França, com sua dupla tradição de um Estado poderoso e uma poderosa crença na democracia - uma crença que, desde a Revolução Francesa, produziu quase tantas revoluções e constituições quanto gerações -, as pessoas confiam no processo político e aceitam apenas um controle judicial bastante fraco da legislatura. Na Alemanha, onde, nos séculos XVIII e XIX, a burguesia era fraca demais para fazer uma revolução e inventou tribunais administrativos para a proteção da liberdade e propriedade dos cidadãos, os tribunais e a lei gozam de mais confiança do que a legislatura e a política. A Alemanha também está entre os países onde o processo político democrático levou ao fascismo ou ao comunismo. Esses países compartilham uma esperança particular de que uma corte constitucional ou suprema, sábia e forte, dobre as tendências perigosas que o processo político e legislativo possa ter. Outro fator importante para a distribuição do ônus da prova e também para a atribuição da tarefa de equilibrar é a homogeneidade ou heterogeneidade das pessoas. Quanto mais conflitos étnicos e religiosos existem, mais faz sentido transferir parte do peso da integração da política para a lei e da legislatura para a corte constitucional ou suprema. O Canadá e a África do Sul são, portanto, países com tribunais ativistas. Também não é surpresa que em Israel, onde a legitimidade como Estado judeu e a legitimidade como Estado democrático não estejam em plena harmonia, o tribunal tenta estabelecer sua própria legitimidade além e independente da política (SCHLINK, 2012, p. 301).

\section{O constitucionalismo democrático acomoda princípios para conciliar valores} constitucionais mais duradouros com objetivos políticos imediatos. A democracia exige decisões coletivas, justas e constitucionalmente compatíveis. Afinal, nas palavras de Kelsen (2003, p. 126), “constituição, lei, regulamento, ato administrativo e sentença, ato de execução, são simplesmente as etapas típicas da formação da vontade coletiva no Estado Moderno". Por isso, mesmo, então, quanto mais importante é o direito fundamental que está em jogo, mais profundo deve ser o escrutínio judicial. É justamente a proporcionalidade que regula a fronteira entre a revisão judicial e as escolhas dos governantes, para equilíbrio dos poderes no Estado constitucional.

A bem da verdade, sobre divisão de poderes, é inegável que pouca deferência faz com que o tribunal usurpe competência democraticamente estabelecida. $\mathrm{Na}$ análise de proporcionalidade, a deferência seria prestada através da aplicação de uma margem de apreciação ou de discrição, nomeadamente para lidar com a ameaça de usurpação jurisdicional.

A crença de que a própria ponderação do legislador é digna de respeito está calcada no pressuposto de que o legislativo respeita os direitos fundamentais, o que ocorre em Estados de bem-estar social e de consolidada tradição constitucional, notadamente em circunstâncias normais de estabilidade, mas não em situações de crise, desacordos ideológicos, perturbações e disfunções legislativas ou políticas diversas. Assim, quando e como a deferência deve ser aplicada depende do contexto político, social e cultural de cada nação:

Para os proponentes da proporcionalidade, por exemplo, as obrigações positivas são a área por excelência para dar respeito e acreditar que o equilíbrio do legislativo é digno de respeito. Mas isso é, obviamente, baseado na suposição de que o legislativo 
concedeu o devido respeito aos direitos econômicos e sociais, pelos quais é considerado democraticamente responsável - suposições que podem se manter nos tradicionais estados de bem-estar social, nas chamadas circunstâncias "normais" de estabilidade e solidariedade, mas são muito menos defensáveis em condições de ruptura e crise fiscal, desacordo ideológico, disfunção legislativa e política fiscal internacionalmente controlada - condições muito mais prováveis de se manter, na maioria dos lugares (YOUNG, 2017, p. 26).

No mesmo sentido, destaca-se que a ponderação está atrelada ao equilíbrio. Assim, por exemplo, "a autonomia do direito privado coexiste com uma ordem constitucional que se diz abrangente" e "a preocupação com a deferência judicial coexiste com o desejo de um escrutínio intensivo". Mesmo que sejam "projetos bem diferentes", a linguagem da ponderação e do "entendimento dialético" é decisiva para os "esforços de síntese ou acomodação" (BOMHOFF, 2013, p. 120).

Com isso, resultam definitivamente unidas a ponderação de direitos fundamentais, o controle jurisdicional moderado e a deferência judicial ideal às margens de apreciação do legislador democraticamente legitimado.

\section{CONSIDERAÇÕES FINAIS}

O problema da dimensão institucional da aplicação do teste da proporcionalidade pode ser adequadamente superado.

A formulação central é que a aplicação do teste da proporcionalidade, pela jurisdição constitucional, no controle das decisões do legislador democraticamente legitimado, não deve desprezar as margens de apreciação liberados pela constituição. Isso, especialmente quando manifestas as incertezas sobre os pressupostos empíricos e normativos apoiadores das decisões do legislador. Nesses casos, maior deve ser a deferência da jurisdição constitucional. Menor, por outro, deve ser essa mesma deferência quando o decidido pelo legislador mais gravemente pesar sobre os direitos fundamentais.

A teoria da margem de apreciação é decisiva para cuidar da relação de tensão entre democracia, direitos fundamentais e jurisdição. O controle jurisdicional das decisões do legislador sobre intervenções ou restrições a direitos fundamentais, com base na proporcionalidade, não é incompatível com a democracia.

Responder quem deve tomar a decisão definitiva sobre a determinação das premissas empíricas e quem que possui a competência para decidir sobre o que é correto segue, por óbvio, tarefa complexa, mais ainda em democracias não consolidadas e sem tradição, nas quais não raras vezes, o tribunal constitucional não está inclinado, justamente por problemas na 
legitimidade do próprio processo político, a aplicar os critérios de delimitação de competência para ponderação.

A conclusão é paradoxalmente simples: Quanto mais racional for o modelo de interpretação, maior legitimidade terá quem interpreta. O controle será justificado, se for proporcional. A proporcionalidade objetiva justamente garantir uma acomodação defensável de direitos e interesses conflitantes, a fim de compor uma ordem harmoniosa de justiça. Trata-se de um critério estrutural para melhor fundamentar as decisões. Os testes estruturados procuram, assim, oferecer soluções adequadas às tensões entre revisão judicial, democracia e direitos constitucionais.

Entende-se que é possível, apesar de difícil, superar a arbitrariedade judicial, através um discurso jurídico sofisticado, com argumentação racional, clara e fundamentada. Por sua vez, a "devida deferência" só será possível em democracias fortes, quando houver um equilíbrio minimamente satisfatório entre os poderes institucionais, ao passo que, em democracias quase que ilusórias, o controle ponderado, ainda que, por vezes, manifeste-se de maneira forte, pode ser a única forma de combater extremas injustiças e avançar em matéria de direitos fundamentais, tornando-se, no caso concreto, o mais moderado.

A intensidade adequada de controle judicial não pode ser determinada abstratamente e precisa ser sensível ao caso concreto. Claro, tudo desde que haja previsibilidade assegurada e comprometimento com o mais importante: a racionalidade do discurso.

\section{REFERÊNCIAS BIBLIOGRÁFICAS}

ALEINIKOFF, T. A. Constitutional Law in the Age of Balancing, 96 Yale L.J., 1987.

ALEXY, Robert. Theorie der Grundrechte. 2. Aufl. Frankfurt am Main: Suhrkamp, 1994.

ALEXY, Robert. A Theory of Constitutional Rights. Oxford: Oxford University Press, 2002.

ALEXY, Robert. Teoria dos Direitos Fundamentais. Trad. Virgílio Afonso da Silva. São Paulo: Malheiros Editores, 2008.

ALEXY, Robert. Thirteen Replies. In PAVLAKOS, George (Ed.). Law, Rights and Discourse. Oxford: Hart Publishing, 333-366, $2007 \mathrm{~b}$.

ALEXY, Robert. Minha filosofia do direito. In HECK, Luis Afonso (Org.). Direitos fundamentais, teoria dos princípios e argumentação. Porto Alegre: Sergio Antonio Fabris Editor, p. 27-31, 2015.

ALEXY, Robert. Constitucionalismo discursivo. Trad. Luís Afonso Heck. Porto Alegre: Livraria do Advogado, 2007a. 
ALEXY, Robert. Teoria Discursiva do Direito. Rio de Janeiro: Editora Forense, 2014.

ALLAN, T. R. S. Constitutional Rights and the Rule of Law. In KLATT, Matthias. Institutionalized Reason: The Jurisprudence of Robert Alexy. Oxford: Oxford University Press, p. 132-151, 2012.

ALLAN, T. R. S. Democracy, Legality and Proportionality. In: HUSCROFT, Grant; MILLER, Bradley W; WEBER, Gregoire. Proportionality and the Rule of Law. Cambridge: Cambridge University Press, p. 205-233, 2014.

DWORKIN, Ronald. Hard cases. In DWORKIN, Ronald. Taking rights seriously. Cambridge: Harvard University Press, p. 91-130, 1978.

ELY, John. Democracy and distrust. Cambridge: Harvard University Press, 1980.

FORSTHOFF, Ernst. El Estado de la Sociedad Industrial. Trad. Luis López Guerra e Jaime Nicolás Mufliz. Madrid: Instituto de Estudios Politicas, 1975.

GAVIÃO FILHO, Anízio Pires. Colisão de Direitos Fundamentais, Argumentação e Ponderação. Porto Alegre: Livraria do Advogado, 2011.

GRIMM, Dieter. Constitutionalism. Oxford: Oxford University Press, 2016.

KELSEN, Hans. Jurisdição Constitucional. Traduzido por Alexander Krug. São Paulo: Martins Fontes, 2003.

KLATT, Matthias e MEISTER, Moritz. The Constitutional Structure of Proportionality. Oxford: Oxford University Press, 2012.

KLATT, Matthias. Direitos a prestações positivas: quem deve decidir? Controle judicial ponderado. In: ALEXY, Robert; BAEZ, Narciso Leandro Xavier; SILVA, Rogério Luiz Nery da (org.). Dignidade humana, direitos sociais e não-positivismo inclusivo. Trad. Carlos Luiz Strapazzon. Florianópolis, p. 215-266, 2015.

SCHLINK, Bernhard. Proportionality in Constitucional Law: Why everywhere but here? 22 Duke Journal of Comparative \& International Law, p. 291-302, 2012.

SCHWABE, Jürgen. Cinquenta anos de jurisprudência do Tribunal Constitucional Federal Alemão. Montevideo: Fundação Konrad Adenauer, 2005.

SIECKMANN, Jan-R. La teoría de los derechos fundamentales de Robert Alexy. Bogotá: Universidad Externado de Colombia, 2014.

YOUNG, Katharine Galloway. Proportionality, Reasonableness, and Economic Social Rights. In JACKSON Vicki; TUSHNET, Mark. Proportionality. Cambridge: Cambridge University Press, 2017. 